\title{
Factors other than training that influence horse driving scores
}

\author{
Anna Stachurska, Marta Liss and Dorota Pawlak \\ Department of Horse Breeding and Use, Faculty of Biology, Animal Sciences and Bioeconomy, University of Life Sciences in Lublin, Lublin, Poland
}

\begin{abstract}
Summary: The aim of the study was to analyze which factors other than training, influence horse scores in single class driving events. The data concerned 40 events at $3^{*}$ level, held in 10 European countries over the course of three years. Of 824 turnouts at these events, a total of 729 entries with all three competitions (Dressage, Marathon, Cones) completed were considered in the main analysis. The following scores and ranks were used: numbers of penalties in the three competitions, total number of penalties, final classification and classification index, which related the placings to the number of completed turnouts at an event. The following factors were considered: the horse sex, age and coat color as well as the country of athlete origin and the location of the events. The data were analyzed with ANOVA GLM and the significant differences between means were determined using Tukey's test. The analysis revealed that most penalties are received in the Marathon competition, with fewer in Dressage and fewest in Cones. The scores and ranks are significantly influenced by the horses' age: the oldest horses (17-21 years old) and 10-1 1 year-olds perform best and the youngest horses (6-7 years old) perform worst. This can be associated not only with the horses' physical development but also experience and skills. Horse sex usually does not significantly affect the scores and ranks. A connection between coat color and the performance should be confirmed in future studies. Athletes from Middle Europe achieve better results than those coming from other parts of Europe, in addition to those from outside Europe, the latter of which tending to fare poorly. The variability in the mean scores within Marathon and Cones competitions indicates differences in the course difficulty depending on the location in which the events are run. Breeders, trainers and athletes, when considering the driving scores and ranks in terms of estimation of a horse, should also take into account the horse age and the fact that difficulty of course design at different events may vary substantially.
\end{abstract}

Keywords: horse, driving competition, scores, breeding, performance

Citation: Stachurska A., Liss M., Pawlak D. (2019) Factors other than training that influence horse driving scores. Pferdeheilkunde 35 , 159-165; DOI 10.21836/PEM20190209

Correspondence: Prof. Anna Stachurska, Department of Horse Breeding and Use, Faculty of Biology, Animal Sciences and Bioeconomy, University of Life Sciences in Lublin, Akademicka 13 str., 20-950 Lublin, Poland; anna.stachurska@up.lublin.pl

\section{Introduction}

Although draught horses were for many ages the main power source for transportation of people and commodities, as well as for work in fields, these horses have lost their importance over the last century. However, an extremely attractive equestrian driving discipline developed and some horse breeds are almost exclusively focused on such use. Due to the high financial outlay and enormous effort needed to organize driving training and events, this discipline is less popular than jumping, dressage or eventing. The driving discipline consists of three competitions: Dressage, Marathon and Cones. The final classification for individuals is determined by adding together the penalties received in each competition (FEl Driving Rules 2017). The athlete with the lowest number of penalties is the winner of the event. Athletes who do not complete any one of the competitions are not included in the final classification. The level of difficulty of the events is defined by a progressive star rating system $\left(1^{*}-4^{*}\right)$. The requirements for a level, among others course designs, should be unified with regard to the difficulty. A horse may only take part once in each competition at an event.

The horses are selected during the process of breeding, primarily according to their performance. However, estimation of performance is often subjective. Sport scores are a direct measure of performance; hence, successful scores are often considered as the focus of such breeding. The question remains however whether the scores accurately illustrate the performance. So many factors can influence the scores that the estimation can be significantly biased. On one hand, these are the structural and physiological factors of the horse, e.g. its conditional status, sex, age, breed or even coat color. As to the latter, breeders sometimes prefer certain coat colors in horses believing that the performance of differently colored horses vary. From the genetic point of view, such a relationship is potential because of possible close gene linkages or pleiotropy of some genes (Stachurska et al. 2007). On the other hand, technical abilities acquired during training may be of utmost importance. Simultaneously, a wide range of entirely external factors exist (McKenzie 2017). For instance, the obstacle color may affect whether a jump is clear or not, although the color is not officially determined by the rules (Stachurska et al. 2002, Spaas et al. 2014). Recent studies have revealed the influence of warm-up intensity on the jumping scores (Stachurska et al. 2018). Some important factors describing cross-country obstacles in eventing, were found (Stachurska et al. 2010). Similarly, dressage judging can be subjective, which may considerably affect the scores and classifications (Stachurska and Bartyzel 201 1). Some effects may be limited as it is for example in the case of accurateness of judging, whereas most effects are fixed. However, the action of both kinds of factors should be known by the breeders to enable exact horse estimation and undertake a suitable breeding strategy. 
Some studies consider the welfare and reactions to different stimuli in driving horses (Dziezyc et al. 2011, Jahnke 1994, Kupczyński and Śpitalniak 2015). To the authors' knowledge, there is no study analyzing basic factors that influence sport results in the horse driving discipline. The sport records are difficult to analyze in the case of pair and four-in hand classes, where the final classification concerns a total of two or four horses (FEl Driving Rules 2017). The objective of the present study was to analyze which factors other than training, influence horse scores in single class driving events.

\section{Materials and Methods}

Data were downloaded from the FEl website (https://data. fei.org 2017) and concerned 40 events held in 10 European countries (Austria, the Czech Republic, France, Ger- many, Hungary, Lithuania, Netherlands, Poland, Slovakia, Slovenia) in 20 locations over the course of three years. The events were at $3^{*}$ level. The FEI Driving Rules (2017) provide that horses at this level must be 6 years old or over. Generally, athletes are qualified as $3^{*}$ when they successfully complete two $2^{*}$ events. The countries that athletes came from were split into the following five groups: Northern Europe (Denmark, Finland, Norway, Sweden), Western Europe (Belgium, France, Germany, Great Britain, Italy, Luxemburg, Netherlands, Spain, Switzerland), Middle Europe (Austria, the Czech Republic, Hungary, Poland, Romania), Eastern Europe (Estonia, Latvia, Lithuania, Russia) and outside Europe (Australia, Canada, Chile, U.S.A.). For a more accurate analysis, only single class was considered. Of 824 entries at these events, a total of 729 entries completed all three competitions, and were thus considered in the main analysis.

Table 1 Driving scores and ranks with regard to the horse's sex | Fahrergebnisse und Platzierungen in Abhängigkeit des Geschlechts der Pferde

\begin{tabular}{|c|c|c|c|c|c|c|c|c|}
\hline Horse's sex & $N$ & Item & $\begin{array}{c}\text { Penalties in } \\
\text { Dressage }\end{array}$ & $\begin{array}{l}\text { Penalties in } \\
\text { Marathon }\end{array}$ & $\begin{array}{c}\text { Penalties in } \\
\text { Cones }\end{array}$ & Total penalties & $\begin{array}{c}\text { Final } \\
\text { classification }\end{array}$ & $\begin{array}{c}\text { Classification } \\
\text { index }\end{array}$ \\
\hline \multirow{2}{*}{ Mares } & 198 & $\bar{x}$ & $59.05 a$ & $91.01 a$ & $8.93 a$ & $158.89 a$ & $13.31 a$ & $0.50 a$ \\
\hline & & sd & 8.39 & 16.72 & 7.30 & 23.09 & 9.33 & 0.24 \\
\hline \multirow{2}{*}{ Stallions } & 80 & $\bar{x}$ & $57.38 a$ & $87.09 a$ & $8.20 a$ & $152.63 a$ & $10.40 b$ & $0.41 a$ \\
\hline & & sd & 8.49 & 14.99 & 7.82 & 23.42 & 8.85 & 0.27 \\
\hline \multirow{2}{*}{ Geldings } & 451 & $\bar{x}$ & $58.53 a$ & $88.78 a$ & $8.77 a$ & $156.11 a$ & $12.44 a$ & $0.47 a$ \\
\hline & & $\mathrm{sd}$ & 8.03 & 18.80 & 7.85 & 26.07 & 9.93 & 0.26 \\
\hline
\end{tabular}

$\mathrm{N}$ - number of entries, $\bar{x}$ - mean, sd- standard deviation. Means marked in columns with different letters significantly differ at $\mathrm{P} \leq 0.05$.

Table 2 Driving scores and ranks with regard to the horse's age | Fahrergebnisse und Platzierungen in Abhängigkeit des Pferdealters

\begin{tabular}{|c|c|c|c|c|c|c|c|c|}
\hline Age (years) & $\mathrm{N}$ & Item & $\begin{array}{l}\text { Penalties in } \\
\text { Dressage }\end{array}$ & $\begin{array}{l}\text { Penalties in } \\
\text { Marathon }\end{array}$ & $\begin{array}{c}\text { Penalties in } \\
\text { Cones }\end{array}$ & Total penalties & $\begin{array}{c}\text { Final } \\
\text { classification }\end{array}$ & $\begin{array}{c}\text { Classification } \\
\text { index }\end{array}$ \\
\hline \multirow[b]{2}{*}{$6-7$} & \multirow[b]{2}{*}{59} & $\bar{x}$ & $60.24 a$ & $96.92 a$ & $14.17 a$ & $171.30 a$ & $13.25 a$ & $0.59 a$ \\
\hline & & $\mathrm{sd}$ & 5.49 & 17.20 & 10.62 & 25.25 & 9.96 & 0.23 \\
\hline \multirow{2}{*}{8} & \multirow{2}{*}{79} & $\bar{x}$ & $59.53 a$ & $91.44 b$ & $10.18 b$ & $160.95 b$ & $12.94 \mathrm{ab}$ & $0.51 b$ \\
\hline & & sd & 8.20 & 15.42 & 7.99 & 23.95 & 8.43 & 0.24 \\
\hline \multirow{2}{*}{9} & \multirow{2}{*}{111} & $\bar{x}$ & $58.51 a$ & $89.98 b$ & $9.15 b$ & $157.62 b$ & $14.14 a$ & $0.50 b$ \\
\hline & & $\mathrm{sd}$ & 8.56 & 21.76 & 7.25 & 28.16 & 10.71 & 0.25 \\
\hline \multirow{2}{*}{10} & \multirow{2}{*}{114} & $\bar{x}$ & $56.32 b$ & $89.43 b$ & $8.25 b$ & $153.99 c$ & $10.83 b$ & $0.44 b c$ \\
\hline & & sd & 7.24 & 17.46 & 7.55 & 25.08 & 7.00 & 0.28 \\
\hline \multirow{2}{*}{11} & \multirow{2}{*}{97} & $\bar{x}$ & $57.82 a b$ & $91.50 \mathrm{~b}$ & $6.67 c$ & $155.99 b c$ & $11.03 b$ & $0.41 c$ \\
\hline & & sd & 8.23 & 17.70 & 6.85 & 23.71 & 9.10 & 0.26 \\
\hline \multirow{2}{*}{12} & \multirow{2}{*}{91} & $\bar{x}$ & $58.75 a$ & $88.43 b$ & $7.70 b c$ & $154.92 c$ & $11.76 b$ & $0.46 b c$ \\
\hline & & sd & 8.77 & 17.95 & 6.48 & 23.68 & 9.00 & 0.28 \\
\hline \multirow{2}{*}{13} & \multirow{2}{*}{46} & $\bar{x}$ & $61.04 a$ & $88.37 b$ & $7.85 b c$ & $157.26 b$ & $13.74 a$ & $0.52 b$ \\
\hline & & sd & 8.68 & 17.03 & 6.55 & 25.19 & 9.60 & 0.26 \\
\hline \multirow[b]{2}{*}{14} & \multirow[b]{2}{*}{46} & $\bar{x}$ & $59.99 a$ & $85.05 b c$ & $7.33 b c$ & $152.74 c$ & $12.91 \mathrm{ab}$ & $0.47 b$ \\
\hline & & sd & 9.50 & 13.37 & 6.68 & 21.63 & 9.79 & 0.26 \\
\hline \multirow{2}{*}{$15-16$} & \multirow{2}{*}{43} & $\bar{x}$ & $60.24 a$ & $82.63 c$ & $9.16 \mathrm{~b}$ & $152.00 c$ & $14.77 a$ & $0.47 b$ \\
\hline & & $\mathrm{sd}$ & 8.28 & 14.66 & 8.37 & 20.63 & 10.49 & 0.23 \\
\hline \multirow{2}{*}{$17-21$} & \multirow{2}{*}{43} & $\bar{x}$ & $55.68 b$ & $80.19 c$ & $7.92 b c$ & $143.65 d$ & $10.91 b$ & $0.37 d$ \\
\hline & & sd & 7.32 & 16.05 & 6.15 & 22.07 & 9.29 & 0.25 \\
\hline
\end{tabular}

$\mathrm{N}$ - number of entries, $\overline{\mathrm{x}}$ - mean, sd - standard deviation. Means marked in columns with different letters significantly differ at $\mathrm{P} \leq 0.05$. 
The following scores and ranks were used: (a) numbers of penalties in the three competitions (Dressage, Marathon, Cones), (b) total number of penalties, (c) final classification and (d) a classification index created in this study. The classification index related the placings to the number of turnouts completed at an event to make the final rank more objective. Five factors were considered: (A) horse sex (mares, stallions, geldings), (B) horse age group $(6-7,8,9,10,11,12,13,14,15-16$, 17-21 year-olds), (C) horse coat color (bay, chestnut, black, gray, roan, piebald) as well as the aforementioned European region that athletes came from (D) and (E), the location at which the events were run. Factor (E) directly concerned particular events, and hence it did not make sense to consider the ranks (c, d) in this case. Information on horse breed is usually unavailable, and thus this could not be included as a factor. The data were analyzed with ANOVA GLM and significant differences between means were determined using Tukey's test. Statistical significance was accepted at $\mathrm{P}<0.05$.

\section{Results}

Ninety five turnouts were eliminated/disqualified/retired/withdrawn from the events: $0.7 \%$ of the initial number of competitors dropped out from the Dressage competition, $7.9 \%$ from the competing turnouts in the Marathon and $3.1 \%$ from the remaining turnouts in Cones. The percentage of penalties imposed in Dressage, Marathon and Cones were 37.4, 57.0 and 5.6, respectively. ANOVA GLM results are presented in Tables 1-5. The interactions between the factors studied were not significant. Generally, the scores and ranks did not statistically differ with regard to sex (Table 1). Only stallions were classified higher than geldings and mares, although the classification index was similar for the three sex groups.

Most entries were 9 to 12 year-old horses (Table 2). The lowest penalties in Dressage were received by 17-21 and 10 year-olds and in Marathon by 15-21 year-olds, whereas 11 -year-olds received the lowest penalties in Cones. Total penalties were the lowest for 17-21 year-old horses. The entries of horses at the age of 10-12 and 17-21 years old held the highest classifications. According to the classification index, 17-21 year-old horses were best followed by 10-11 year-olds. The worst results in all parameters were observed in 6-7 year-olds.

Bay horses most often took part in the events (Table 3). There were also many entries of gray and chestnut horses. Piebald horses were rare, whereas roans competed only twice. All parameters were best in the case of piebald horses. Gray and chestnut horse entries resulted in not only the highest penalties in Cones but for total penalties overall. The chestnuts and roans were classified in last place.

Most turnouts came from Western and Middle Europe (Table 4). The horses from Middle Europe were rated amongst the best in terms of all parameters. Western Europe was poorer than Middle Europe in regards to the Marathon competition. The worst scores except for in Dressage, and ranks, were received by turnouts coming from outside Europe. Both final ranks were similar for all parts of Europe and significantly worse for turnouts from outside Europe.

The lowest penalties in Dressage were imposed in Dillenburg (Table 5). In Marathon, the turnouts had the lowest penalties in Piber Köflach and followed by Chablis and Wałbrzych Ksiazz. The penalties for this competition in Fabiansebestyen, Mezohegyes and Topolcianky, were highest. In turn, the penalties in Cones were lowest in Chablis and Le Pin au Haras, whereas they were highest in Mezohegyes. The turnouts obtained the lowest total penalties in Chablis, Pau, Piber Köflach and Wałbrzych - Ksiąz, and the highest total penalties in Mezohegyes and Topolcianky.

\section{Discussion}

Driving events that include three competitions run in totally different circumstances are very attractive for audiences and represent a great challenge for athletes and horses. The difficulties in conducting statistical analyzes for eventing, which is similar in its structure to driving, was pointed out earlier

\begin{tabular}{|c|c|c|c|c|c|c|c|c|}
\hline Table 3 & \multicolumn{4}{|c|}{ Driving scores and ranks with regard to the horse's coat color } & \multicolumn{4}{|c|}{ Fahrergebnisse und Platzierungen in Abhängigkeit von der Fellfarbe } \\
\hline Coat color & $\mathrm{N}$ & Item & $\begin{array}{c}\text { Penalties in } \\
\text { Dressage }\end{array}$ & $\begin{array}{l}\text { Penalties in } \\
\text { Marathon }\end{array}$ & $\begin{array}{c}\text { Penalties in } \\
\text { Cones }\end{array}$ & Total penalties & $\begin{array}{c}\text { Final } \\
\text { classification }\end{array}$ & $\begin{array}{c}\text { Classification } \\
\text { index }\end{array}$ \\
\hline \multirow[t]{2}{*}{ Bay } & \multirow{2}{*}{460} & $\bar{x}$ & $58.02 a$ & $88.90 a$ & $8.10 a$ & $154.95 a$ & $11.97 a$ & $0.45 a$ \\
\hline & & sd & 8.09 & 18.01 & 7.40 & 24.79 & 9.57 & 0.26 \\
\hline \multirow{2}{*}{ Chestnut } & \multirow{2}{*}{95} & $\bar{x}$ & $58.39 a$ & $91.72 a$ & $10.26 b$ & $160.41 b$ & $14.89 \mathrm{~b}$ & $0.51 a$ \\
\hline & & sd & 7.15 & 17.95 & 8.46 & 25.41 & 11.13 & 0.25 \\
\hline \multirow{2}{*}{ Black } & \multirow{2}{*}{58} & $\bar{x}$ & $57.50 a$ & $88.02 a$ & $8.78 a$ & $154.73 a$ & $12.71 \mathrm{a}$ & $0.50 a$ \\
\hline & & sd & 9.21 & 15.98 & 6.38 & 24.30 & 9.79 & 0.28 \\
\hline \multirow{2}{*}{ Grey } & \multirow{2}{*}{104} & $\bar{x}$ & $61.78 a$ & $89.29 a$ & $10.44 b$ & $161.49 a b$ & $12.68 a$ & $0.52 a$ \\
\hline & & sd & 7.77 & 18.84 & 8.45 & 26.11 & 8.52 & 0.24 \\
\hline \multirow[b]{2}{*}{ Roan } & \multirow[b]{2}{*}{2} & $\bar{x}$ & $69.79 b$ & $76.38 b$ & $7.78 a$ & $153.95 a$ & $17.00 c$ & $0.49 a$ \\
\hline & & sd & 15.80 & 3.59 & 5.04 & 29.42 & 12.73 & 0.36 \\
\hline \multirow[b]{2}{*}{ Piebald } & \multirow[b]{2}{*}{10} & $\bar{x}$ & $49.89 c$ & $80.77 b$ & $4.16 c$ & $134.82 c$ & $5.80 d$ & $0.23 b$ \\
\hline & & sd & 4.16 & 7.15 & 3.16 & 8.13 & 3.49 & 0.11 \\
\hline
\end{tabular}

$\mathrm{N}$ - number of entries, $\overline{\mathrm{x}}$ - mean, sd-standard deviation. Means marked in columns with different letters significantly differ at $\mathrm{P} \leq 0.05$. 
(Whitaker and Hill 2005). According to FEI Driving Rules (2017), Dressage, Marathon and Cones competitions included in the horse driving discipline are considered together in the final classification. That means the penalties in particular competitions may be also analyzed as a whole. The classification index made for this study allowed to make the final rank independent of the number of turnouts at an event. As mentioned, pair and four-in hand classes are an additional limitation to analyses of horse driving performance. However, in the present study a large volume of material from single class driving at high-leveled events was collected, which enabled a comprehensive analysis.

The percentages of both incompleted competitions and penalties clearly show that the Marathon is incomparably more difficult than the other two driving competitions. It seems that these results are in agreement with intentions of the driving discipline creators (FEl Driving Rules 2017). The Marathon is most spectacular and demanding competition, hence its scores should also weigh the most. As it might be expected, the Cones were rated second according to the number of incompleted entries, however in terms of penalties, the second was Dressage.

The results show that it is mainly geldings that compete in driving. Mares participating in driving events were over twice as rare as geldings and stallions over five times as rare. It is likely that athletes and trainers do not choose stallions for driving because of their higher emotionality (Janczarek and Kędzierski 2011) and difficulties in separating them from other horses during transport and events. A tendency for slightly better variables in stallions perhaps does not sufficiently justify the use of stallions in the discipline. In eventing, stallions and geldings usually outperform mares (Hanousek et al. 2018).

The parameters turned out to be closely related to horse age. The oldest horses in the study, i.e. those between 17-21 years old were best in terms of all parameters; horses aged between 10 and 12 years were also classified highly, whereas young, 6-7 year olds had the worst results. This is an emphatic proof that experience and acquired skills are most important in the driving discipline. Old horses may be in relatively poorer physical condition (Zsoldos et al. 2014), however they still preponderate over young and strong but inexperienced horses. These results cannot be interpret that e.g. younger horses competed on more difficult courses because at a particular event, horse age groups were differentiated and the interaction between the age group and event was not significant.

Differences in the parameters between differently colored driving horses may indicate that the coat color is associated with the performance. However, racing scores of Thoroughbreds of basic and gray colors did not show such a relationship (Stachurska et al. 2007). On the other hand, some behavioural differences were found between horses of basic colors (Finn et al. 2016, Jacobs et al. 2016). The present analysis may be considered only as a pilot study with regard to this factor, since the piebald horses, which performed significantly better, competed rarely and the association could have been coincidental. Instead, a tendency for better parameters in bays and blacks, and worse parameters for chestnuts may indicate that there is a weak connection between these colors with the driving performance.

Interestingly, best variables were achieved by athletes from Middle Europe, who made up to $30 \%$ of entries. This may indicate that the horse driving discipline has become a domain of Austria, Czech, Hungary and Poland. In turn, the poor parameters observed for turnouts from outside Europe might be caused by long transport and difficulty in adaptation to different climatic conditions. These athletes were few. Many reasons could determine their decision to participate at European events, hence it is not possible to estimate the level of driving in their countries on the basis of this analysis.

It should be taken into account that Dressage scores are less objective than the results of Marathon and Cones because of the way of judging. .However, the Dressage competition is highly standardized and perhaps that is why penalties in Dressage hardly differed between various events. Low differences in these parameters indicate a high quality of judging and similar level of turnouts at different events. Instead, the high mean variation in Marathon and Cones penalties (from 72 to 113 and from 4 to 20 , respectively) is opposite to the goal of the star rating system. This may illustrate great differences in the course difficulty depending on the location in which the events are run.

Table 4 Driving scores and ranks with regard to the part of Europe that athletes came from $\mid$ Fahrergebnisse und Platzierungen in Abhängigkeit der Herkunft der Pferde

\begin{tabular}{|c|c|c|c|c|c|c|c|c|}
\hline $\begin{array}{c}\text { Part of Europe } \\
\text { of athlete }\end{array}$ & $\mathrm{N}$ & Item & $\begin{array}{l}\text { Penalties in } \\
\text { Dressage }\end{array}$ & $\begin{array}{l}\text { Penalties in } \\
\text { Marathon }\end{array}$ & $\begin{array}{l}\text { Penalties in } \\
\text { Cones }\end{array}$ & Total penalties & $\begin{array}{c}\text { Final } \\
\text { classification }\end{array}$ & $\begin{array}{c}\text { Classification } \\
\text { index }\end{array}$ \\
\hline \multirow{2}{*}{$\begin{array}{l}\text { Northern } \\
\text { Europe }\end{array}$} & \multirow{2}{*}{88} & $\bar{x}$ & $61.01 a$ & $89.08 a$ & $8.64 a b$ & $156.34 a b$ & $13.32 b$ & $0.51 \mathrm{ab}$ \\
\hline & & sd & 6.99 & 15.66 & 6.18 & 22.56 & 8.19 & 0.25 \\
\hline \multirow{2}{*}{$\begin{array}{l}\text { Western } \\
\text { Europe }\end{array}$} & \multirow{2}{*}{379} & $\bar{x}$ & $57.44 b$ & $89.97 a$ & $7.63 b c$ & $154.89 b$ & $12.42 b$ & $0.45 b$ \\
\hline & & sd & 8.14 & 20.91 & 5.36 & 25.74 & 8.75 & 0.25 \\
\hline \multirow{2}{*}{$\begin{array}{l}\text { Middle } \\
\text { Europe }\end{array}$} & \multirow[b]{2}{*}{223} & $\bar{x}$ & $58.82 b$ & $85.76 b$ & $6.53 c$ & $148.71 b$ & $11.26 \mathrm{~b}$ & $0.39 b$ \\
\hline & & sd & 8.46 & 15.44 & 4.77 & 20.67 & 7.28 & 0.27 \\
\hline \multirow{2}{*}{$\begin{array}{l}\text { Eastern } \\
\text { Europe }\end{array}$} & \multirow{2}{*}{13} & $\bar{x}$ & $64.58 c$ & $85.57 b$ & $7.45 b c$ & $152.17 b$ & $13.82 \mathrm{~b}$ & $0.44 b$ \\
\hline & & sd & 6.66 & 16.34 & 6.09 & 23.29 & 10.51 & 0.26 \\
\hline \multirow{2}{*}{$\begin{array}{l}\text { Outside } \\
\text { Europe }\end{array}$} & \multirow{2}{*}{26} & $\bar{x}$ & $60.95 a$ & $89.85 a$ & $9.87 a$ & $161.24 a$ & $19.19 a$ & $0.59 a$ \\
\hline & & sd & 7.12 & 13.52 & 5.95 & 18.03 & 11.65 & 0.20 \\
\hline
\end{tabular}

$\mathrm{N}$ - number of entries, $\bar{x}$ - mean, $\mathrm{sd}$ - standard deviation. Means marked in columns with different letters significantly differ at $\mathrm{P} \leq 0.05$. 


\section{Conclusion}

The study performed on a great material shows some factors that influence the scores and ranks in single class horse driving events. Most penalties are received in the Marathon competition; fewer are received in Dressage and fewest in Cones. The age of the horse significantly influences the variables. The oldest horses (17-21 years old) and 10-11 year-olds perform best, likely due to their higher levels of experience and skills. These horses distinctly preponderate over young, 6-7 year old horses. The horse's sex is usually an insignificant factor. Athletes from Middle Europe achieve better scores and ranks than those coming from other parts of Europe in addition to those from outside Europe, which tended to fare poorly. The

Table 5 Driving scores with regard to the location of the event | Fahrergebnisse in Abhängigkeit des Veranstaltungsortes

\begin{tabular}{|c|c|c|c|c|c|c|c|c|}
\hline Country & Location & M & $N$ & Item & $\begin{array}{l}\text { Penalties in } \\
\text { Dressage }\end{array}$ & $\begin{array}{l}\text { Penalties in } \\
\text { Marathon }\end{array}$ & Penalties in Cones & Total penalties \\
\hline \multirow{4}{*}{ Austria } & \multirow{2}{*}{ Altenfelden } & \multirow{2}{*}{2} & \multirow{2}{*}{38} & $\bar{x}$ & $58.45 a$ & $83.72 b$ & $9.07 c$ & $151.28 b$ \\
\hline & & & & sd & 6.77 & 9.16 & 7.59 & 15.79 \\
\hline & \multirow{2}{*}{ Piber Köflach } & \multirow{2}{*}{2} & \multirow{2}{*}{47} & $\bar{x}$ & $56.12 a b$ & $72.11 d$ & $8.82 a c$ & $136.94 d$ \\
\hline & & & & $\mathrm{sd}$ & 7.73 & 17.39 & 5.81 & 22.51 \\
\hline \multirow{6}{*}{ Czech } & \multirow{2}{*}{ Kladruby nad Labem } & \multirow{2}{*}{3} & \multirow{2}{*}{69} & $\bar{x}$ & $60.82 a$ & $96.71 a$ & $7.60 a$ & $165.10 a$ \\
\hline & & & & sd & 9.17 & 19.41 & 5.00 & 27.83 \\
\hline & \multirow[b]{2}{*}{ Nebanice } & \multirow[b]{2}{*}{2} & \multirow[b]{2}{*}{28} & $\bar{x}$ & $59.07 a$ & $83.15 b$ & $9.89 c$ & $151.85 b$ \\
\hline & & & & sd & 9.37 & 19.13 & 7.33 & 30.85 \\
\hline & \multirow{2}{*}{ Nemcice u Kolina } & \multirow{2}{*}{3} & \multirow{2}{*}{28} & $\bar{x}$ & $60.64 a$ & $88.29 b$ & $7.64 a$ & $157.57 a b$ \\
\hline & & & & sd & 12.00 & 18.90 & 5.66 & 32.59 \\
\hline \multirow{8}{*}{ France } & \multirow{2}{*}{ Chablis } & \multirow{2}{*}{3} & \multirow{2}{*}{69} & $\bar{x}$ & $60.06 a$ & $77.74 \mathrm{bd}$ & $4.72 d$ & $142.52 d$ \\
\hline & & & & sd & 8.45 & 12.75 & 5.58 & 20.42 \\
\hline & \multirow{2}{*}{ Le Pin au Haras } & \multirow{2}{*}{2} & \multirow{2}{*}{17} & $\bar{x}$ & $56.70 a b$ & $99.61 \mathrm{ac}$ & $4.14 d$ & $160.45 a b$ \\
\hline & & & & sd & 8.37 & 17.98 & 6.28 & 24.88 \\
\hline & & & & $\bar{x}$ & $55.65 a b$ & $81.16 \mathrm{bd}$ & $6.19 a$ & $143.00 d$ \\
\hline & Pau & 1 & 6 & sd & 6.41 & 7.06 & 3.90 & 13.47 \\
\hline & & & & $\bar{x}$ & $59.05 a$ & $94.08 a$ & $9.75 c$ & $162.65 a$ \\
\hline & Saumur & 3 & 45 & sd & 7.59 & 21.79 & 7.52 & 25.23 \\
\hline & & & & $\bar{x}$ & $53.24 b$ & $90.00 \mathrm{ab}$ & $8.99 a c$ & $152.10 b$ \\
\hline & Dillenburg & 3 & 18 & sd & 7.68 & 21.10 & 5.91 & 26.88 \\
\hline Seminimy & & & & $\bar{x}$ & $61.10 a$ & $88.37 b$ & $7.88 a$ & $157.16 \mathrm{ab}$ \\
\hline & Drebkau & 2 & 51 & sd & 6.96 & 9.55 & 7.51 & 15.82 \\
\hline & A & 1 & & $\bar{x}$ & $56.91 \mathrm{ab}$ & $85.80 b$ & $15.65 \mathrm{e}$ & 158.37ab \\
\hline & Aszár Kisber & 1 & 28 & $\mathrm{sd}$ & 6.28 & 10.08 & 10.21 & 25.02 \\
\hline 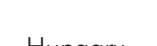 & Fabion & 2 & 25 & $\bar{x}$ & $57.28 a$ & $105.07 \mathrm{c}$ & $10.73 c$ & $173.29 c$ \\
\hline Hungary & rabiansebestyen & 2 & 35 & $\mathrm{sd}$ & 7.60 & 17.86 & 7.78 & 23.62 \\
\hline & & & & $\bar{x}$ & $56.11 \mathrm{ab}$ & $107.82 c$ & $20.07 f$ & $184.00 \mathrm{e}$ \\
\hline & Mezohegyes & 1 & 3 & sd & 5.54 & 8.33 & 13.00 & 13.79 \\
\hline Lithurnia & Bendoriai & 2 & 23 & $\bar{x}$ & $59.01 a$ & $89.33 b$ & $9.26 c$ & 157.59ab \\
\hline Lithuanıa & Bendorıaı & 2 & 23 & $\mathrm{sd}$ & 7.79 & 11.08 & 5.97 & 18.96 \\
\hline & & & & $\bar{x}$ & $59.51 a$ & $90.40 a b$ & $9.15 c$ & $159.06 \mathrm{ab}$ \\
\hline Netherlands & Horst & 2 & 83 & sd & 6.72 & 9.03 & 6.79 & 16.98 \\
\hline & & & & $\bar{x}$ & $59.90 a$ & $96.58 a$ & $14.04 \mathrm{e}$ & $170.53 a$ \\
\hline & Bogusławice & 1 & 13 & sd & 6.92 & 14.60 & 4.94 & 19.51 \\
\hline 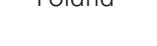 & Wathrouch Kriai & 1 & 12 & $\bar{x}$ & $56.11 \mathrm{ab}$ & $77.60 \mathrm{bd}$ & $6.81 a$ & $140.53 d$ \\
\hline & Wałbrzych - Ksıąz & 1 & 12 & sd & 6.66 & 5.06 & 3.74 & 12.00 \\
\hline Clouglia & & & 21 & $\bar{x}$ & $59.78 a$ & $87.25 b$ & $5.99 b$ & $152.99 b$ \\
\hline Slovakıa & Lipica & 3 & 31 & sd & 8.31 & 13.83 & 3.72 & 19.00 \\
\hline Slovenig & Tonolcianty & 1 & 25 & $\bar{x}$ & $61.42 a$ & $112.97 c$ & $13.23 \mathrm{e}$ & $187.62 \mathrm{e}$ \\
\hline slovenia & Iopolcianky & 1 & 25 & sd & 7.03 & 12.62 & 9.20 & 21.51 \\
\hline
\end{tabular}

$M$ - number of events, $N$ - number of entries, $\bar{x}-$ mean, sd - standard deviation. Means marked in columns with different letters significantly differ at $P \leq 0.05$. 
variability in the mean scores within the Marathon and Cones competitions indicates differences in course difficulty between particular places where the events are run. Breeders, trainers and athletes, when considering the driving scores and ranks in terms of estimation of a horse, should take into account the horse age and the fact that difficulty of course design at different events may vary substantially.

\section{Funding statement}

This study was supported by Faculty of Biology, Animal Sciences and Bioeconomy, University of Life Sciences in Lublin.

\section{Conflict of interest}

The authors declare that they have no conflict of interest.

\section{Animal welfare statement}

The study did not need an approval of Ethical Committee for Animal Experiments since the data were downloaded from the Internet.

\section{References}

Dziezyc J., Taylor L., Boggess M. M., Scott H. M. (2011) The effect of ocular blinkers on the horses' reactions to four different visual and audible stimuli: results of a crossover trial. Vet. Ophthalmol. 14, 327-332; DOI 10.1111/j.1463-5224.2011.00880

FEI Driving Rules (2017) Fédération Equestre Internationale, Lausanne, Switzerland

Finn J. L., Haase B., Willet C. E., Rooy D., Chew T., Wade C. M., Hamilton N. A., Velie B. D. (2016) The relationship between coat color phenotype and equine behavior: A pilot study. Appl. Anim. Behav. Sci. 174, 66-69; DOI 10.1016/i.applanim.2015.11.004

Hanousek K., Salavati M., Fouladi-Nashta A. (2018) Effect of horse sex status on British Eventing competition performance: an observational study between 1998 and 2016. Vet. Rec. 182, 666; DOI 10.1136/vr.104719 https://data.fei.org/ (accessed in 2017)

Jacobs L. N., Staiger E. A., Albright J. D., Brooks S. A. (2016) The MC1R and ASIP coat color loci may impact behavior in the horse. J. Hered. 107, 214-219; DOI 10.1093/ihered/esw007
Jahnke H. D. (1994) Animal welfare and safety aspects for coach driving. Dtsch. Tierarztl. Wschr. 101, 123-125

Janczarek I., Kędzierski W. (2011) Emotional response to novelty and to expectation to novelty in young race horses. J. Equine Vet. Sci. 31, 549-554; DOI 10.1016/i.jevs.2011.03.012

Kupczyński R., Śpitalniak K. (2015) Analysis of acid-base balance as well as hematological and biochemical parameters in horses of combined driving discipline. Arch. Anim. Breed. 58, 221-228; DOI 10.5194/ aab-58-221-2015

McKenzie E. (2017) Foundations of performance - factors that contribute to excellence in equine exercise. Comp. Exerc. Physiol. 13, 127-135; https://DOI 10.3920/CEP170022

Reef V. B., Bonagura J., Buhl R., McGurrin M. K., Schwarzwald C. C., van Loon G., Young L. E. (2014) Recommendations for management of equine athletes with cardiovascular abnormalities. J. Vet. Intern. Med. 28, 749-761; DOI [10.1111/jvim. 12340]

Spaas J., Helsen W. F., Adriaenssens M., Broeckx S., Duchateau L., Spaas J. H. (2014) Correlation between dichromatic color vision and jumping performance in horses. Vet. J. 202, 166-171; http://hdl.handle. net/1854/LU-5783191

Stachurska A., Bartyzel K. (2011) Judging dressage competition in the view of improving horse performance assessment. Acta Agr. Scand. AAn. 61, 92-102; https://DOI 10.1080/09064702.201 1.600323

Stachurska A., Janczarek I., Wilk I., Jaworska K., Pluta M., Kolstrung R. (2018) Effect of warm-up intensity on horse-rider dyad's performance in jumping. Cienc. Rural 48 (2) 2018; DOI 10.1590/01038478 cr20170638

Stachurska A., Pięta M., Łojek J., Szulowska J. (2007) Performance in racehorses of various colours. Livest. Sci. 106, 282-286; DOI 10.1016/j. livsci.2006.07.017

Stachurska A., Pięta M., Nesteruk E. (2002) Which obstacles are most problematic for jumping horses? Appl. Anim. Behav. Sci. 77, 197207; DOI 10.1016/S0168-1591(02)00042-4

Stachurska A., Pięta M., Phaff Ussing A., Kaproń A., Kwiecińska N. (2010) Difficulty of cross-country obstacles for horses competing in Three Day Events. Appl. Anim. Behav. Sci. 123, 101-107; DOI 10.1016/i.applanim.2010.01.001

Whitaker T. C., Hill J. (2005) Problems associates with the analysis of the pattern of total cross-country eventing penalty scores at advanced level of competition in the United Kingdom. Int. J. Perf. Anal. Spor. 5, 51-60; DOI 10.1080/24748668.2005.11868315

Zsoldos R. R., Krüger B., Licka T. F. (2014) From maturity to old age: tasks of daily require a different muscle use in horses. Comp. Exerc. Physiol. 10, 75-88; DOI 10.3920/CEP140001 